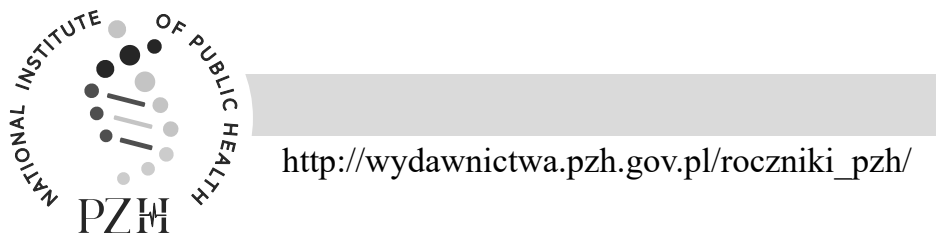

\title{
ASSESSING THE EFFECT OF ORAL DISEASES ON ORAL HEALTH RELATED QUALITY OF LIFE OF INSTITUTIONALIZED ELDERLY USING ORAL HEALTH IMPACT PROFILE (OHIP-14) QUESTIONNAIRE: A PILOT STUDY
}

\author{
Antima Saxena ${ }^{1}$, Ramesh Nagarajappal, Debasruti Naik', Mohammed Abid², Gayathri Ramesh ${ }^{3}$ \\ ${ }^{1}$ Department of Public Health Dentistry, Institute of Dental Sciences, Siksha 'O' Anusandhan \\ (Deemed to be University), Bhubaneswar, Odisha, India \\ ${ }^{2}$ Private Practitioner, Gulbarga, Karnataka, India \\ ${ }^{3}$ Department of Dentistry, Chamarajanagar Institute of Medical Sciences, Chamarajanagar, Karnataka, India
}

\begin{abstract}
Background. India establishes a geriatric population of about 80 million which is $7.2 \%$ of the total population. The geriatric population is often faced by a negative impact on their quality of life due to poor oral health.

Objectives. To assess the impact of oral disease on daily activities and quality of life among the institutionalized elderly in Kanpur, India.

Materials and Method. A total of fifty-six patients were purposively selected from two old age homes through convenience sampling technique. To assess the oral health status WHO basic oral health survey form (1997) was used. Short version of Oral Health Impact Profile (OHIP - 14) questionnaire was used to assess the Oral Health Related Quality of Life (OHRQoL). Independent t-test and ANOVA test was done to determine the relationship between the groups.

Results. Presence or absence of grossly decayed teeth, chronic periodontitis, based on edentulism and remaining sound teeth status produced no significant differences in any of the domains. In comparison with males, females experienced greater impact of oral diseases with respect to mean OHIP-14 score; however, it was non - significant $(p=0.45)$.

Conclusion. Oral health status of the institutionalized subjects in Kanpur city is poor, with edentulism and periodontitis. The effect of oral diseases on the lives of elderly is comparatively low and is non-significant.
\end{abstract}

Key words: elderly, OHIP-14, OHRQoL, impact of oral diseases

\section{INTRODUCTION}

The geriatric population is portrayed by extraordinary conditions because of physiological changes normal for maturing, just as diseases and psychosocial and dietary factors that impact their nourishing status [2].

Generally, the aged population is at greater risk of malnutrition due to inadequate food intake (amount) [11], poor selection of food (quality), illnesses that may lead to nutrient loss and also decrease nutrition absorption, also in elder people the nutrition deficiency can be a cause of physiological, psychological, pathological and social factors $[5,8]$. This situation is aggravated when institutionalized, "the occurrence of nutritional disorders in institutionalized elderly ranging from $30 \%$ to $80 \%$, with a consequent negative impact on their health" [4].

"Oral health is an essential element for general health and quality of life throughout an individual's life course", as written in a WHO report from 2006 about oral health in elderly. Good oral health is a state of being free from oral diseases, infections and pain that restricts normal function and quality of life. The world's population is ageing. Society will face a Challenge in treating oral and general diseases in older individuals as to provide an appropriate treatment, diagnosis of the disease at an early stage is required. According to Razak et al. [14] few factors such as illness and health related factors, socio-demographic factors, servicerelated factors and subjective factors are required for utilization of dental services.

Corresponding author: Ramesh Nagarajappa, ORCID ID: 0000-0002-0253-7720, Department of Public Health Dentistry, Institute of Dental Sciences, Siksha 'O' Anusandhan (Deemed to be University), Bhubaneswar, Odisha, India, mobile: 9591357070, e-mail: rameshpcd@yahoo.co.in 
Due to remarkable increase in the geriatric population, the world is now facing a demographic revolution. According to 2011 census, there are nearly 104 million elderly persons (aged 60 years or above) in India. It is expected that by 2050 , India's population of elderly may increase to 323 million [13].

With increasing age, the problems related to health also increases. Oral health is an integral part of general health. Poor oral health consisting dental problems such as, dental caries, periodontal diseases, mobile tooth, missing tooth and many more leads to compromised general health [7]. Because if one can't eat properly their body suffers. Similarly, the different systemic problems also may have adverse effects on oral health. Poor oral health negatively affects the quality of life.

Also, lately the number of elderlies receiving institutional care has increased tremendously, such residents often have to depend upon caregivers for their general and oral health care. Adequate access to dental care can affect their oral hygiene, oral health function that may lead to compromised overall health and also can affect the quality of life [16].

According to the National Oral Health Survey [12] it was observed that poor oral health led to $29.3 \%$ of high level of tooth loss, $84.7 \%$ of dental caries, $79.4 \%$ of periodontal disease, $10 \%$ of mucosal lesions and $0.5 \%$ of oral cancer.

Surveys suggest limited utilization of dental services by geriatric population. This may be because of numerous considerable factors. Age related compromised mobility is the main factor for limited use of oral health care facility. Along with that financial dependence, physical dependence, physical health are other contributing barriers. The elderly living alone, who are financially deprived or abandoned from their houses look for alternative homes for living and some choose old age homes [3]. Such elderly does not have facilities for oral health care.

The fact is that we do not have much records about elderly in India concerning the oral disease burden and treatment needs. Moreover, the degree to which oral diseases influences the general health and quality of lives of the geriatrics have not been widely studied. Hence, the present study was conducted to assess the effect of oral diseases on daily activities and quality of life among the institutionalized elderly in Kanpur, India.

\section{MATERIALS AND METHODS}

A cross-sectional study was executed among the institutionalized elderly residing in old age homes at Kanpur, India. Reviewing of the study protocol was done and was approved by Institutional Review Board. Residents of two old age homes aged 60 years or more and who gave the written informed consent were included in the study. Inmates with cognitive impairment and with severely debilitated and hearing and/or speech impairment were excluded. A list was arrived at, after short listing through convenience sampling technique and a total of 56 patients were purposively selected.

A self-administered questionnaire was given to the inmates' who participated in the study. The information collected by the questionnaire included: Oral health related quality of life (OHRQoL) by using short version of questionnaire Oral Health Impact Profile (OHIP - 14) [18] and Oral health status of subjects by using Basic Oral Health Survey Form (1997) [19].

The OHIP-14, includes 14 questions which was introduced by Slade in 1997 [18]. The objective of OHIP is to present certain types of numerical data for different situations in terms of health and treatment consequences. It covers seven dimensions: functional limitation, physical pain, psychological discomfort, physical disability, psychological disability, social disability and handicap. Five-point Likert scale was used to grade two questions out of each seven subscales.

The data was collected through personal interview (among those who were illiterate or had other impediments in responding to the questionnaire), by filling in the specially designed questionnaire. The interview included assessment of the effect of oral diseases on the daily living and quality of life of the participants using the socio-dental indicator Oral Health Impact Profile. Using mouth mirror and CPI probe, the clinical examinations were conducted in a well illuminated area at the old age homes. Prior to the start of data collection, the investigator was trained in recording the Basic Oral Health survey proforma and intra examiner reliability was calculated as $(\kappa \geq$ $0.8)$.

Along with the oral health the general health of the participants was also reviewed by the general physician. The clinical records of the inmates were likewise analyzed to get data in regards to the major systemic conditions that influenced them and the treatment given. The questionnaire required 25 to 30 minutes to be completed by each subject.

Statistical analysis was done using computer with the aid of Statistical Package for Social Science (SPSS), version 16, USA. Information procured were esteemed suitable for utilizing parametric tests, since the outcomes were normally distributed as seen by Shapiro Wilk test. Descriptive statistics was used to summarize the variables. Independent ' $t$ ' and ANOVA tests were done to determine the relationship between the groups. For all tests, confidence interval and $\mathrm{p}$ value were set at $95 \%$ and $<0.05$ respectively. 


\section{RESULTS}

A total of 56 old people aged between 71-80 years (mean $74.2 \pm 1.3$ years) were examined. Among them, 37 were males and 19 were females. On recording the DMFT index (Table 1) it was found that maximum number of study subjects had sound teeth $(9.12 \pm 4.12)$ followed by missing teeth $(5.96 \pm 2.69)$, filled teeth $(3.30 \pm 1.06)$ and decayed teeth $(3.39 \pm 0.78)$.
Mean OHIP scores were higher among males across all domains but the difference was not statistically significant $(p>0.05)$. The overall mean OHIP score was $22.65 \pm 6.22$ and $21.37 \pm 5.46$ among males and females respectively. This association was not statistically significant $(\mathrm{p}>0.05)$ (Table 3 ).

Similarly, the mean scores were higher among $>80$ years age group across all the domains and the difference was statistically not significant $(p>0.05)$.

Table 1. Description of study subjects according to caries status

\begin{tabular}{|l|c|c|c|c|c|}
\hline \multicolumn{1}{|c|}{ Components } & $\mathrm{n}$ & Minimum & Maximum & Mean & Std. Deviation \\
\hline Decayed & 56 & 2.00 & 4.00 & 3.39 & 0.78 \\
\hline Missing & 56 & 2.00 & 12.00 & 5.96 & 2.69 \\
\hline Filled & 56 & 2.00 & 5.00 & 3.30 & 1.06 \\
\hline
\end{tabular}

Table 2 shows the distribution of subjects according to the periodontal status as recorded according to the CPITN index. Only 5.3\% subjects had healthy periodontium. Majority of the subjects had shallow pockets $(42.8 \%)$ followed by calculus (19.6\%), deep pockets $(16 \%)$ and bleeding $(12.5 \%)$.
The overall mean OHIP score was $20.70 \pm 6.15$, $23.04 \pm 6.07$ and $23.80 \pm 4.89$ among $<70,70-80$ and $>80$ years subjects respectively. It was not statistically significant $(p>0.05)$ (Table 4).

Table 2. Description of study subjects according to periodontal status

\begin{tabular}{|l|c|c|}
\hline \multicolumn{1}{|c|}{ Codes } & $\mathrm{n}$ & \multicolumn{1}{c|}{. } \\
\hline $0=$ Healthy & 3 & 12.5 \\
\hline $1=$ Bleeding & 7 & 19.6 \\
\hline $2=$ Calculus & 11 & 42.8 \\
\hline $3=$ Shallow Pockets & 24 & 16 \\
\hline $4=$ Deep Pockets & 9 & 3.5 \\
\hline$X / 9=$ Not Recorded & 2 & \\
\hline
\end{tabular}

Table 3. Gender-wise comparison of OHIP-14 scores and its domains

\begin{tabular}{|c|c|c|c|c|c|c|}
\hline Domain & Gender & $\mathrm{n}$ & Mean & $\mathrm{SD}$ & $\mathrm{t}$ value & $\mathrm{p}$ value \\
\hline \multirow{2}{*}{ Functional limitation } & Male & 37 & 3.14 & 1.00 & \multirow{2}{*}{0.658} & \multirow{2}{*}{0.514} \\
\hline & Female & 19 & 2.95 & 1.03 & & \\
\hline \multirow{2}{*}{ Physical pain } & Male & 37 & 3.19 & 1.00 & \multirow{2}{*}{0.852} & \multirow{2}{*}{0.398} \\
\hline & Female & 19 & 2.95 & 1.03 & & \\
\hline \multirow{2}{*}{ Physical discomfort } & Male & 37 & 3.19 & 1.00 & \multirow{2}{*}{0.852} & \multirow{2}{*}{0.398} \\
\hline & Female & 19 & 2.95 & 1.03 & & \\
\hline \multirow{2}{*}{ Physical disability } & Male & 37 & 3.24 & 0.89 & \multirow{2}{*}{0.787} & \multirow{2}{*}{0.435} \\
\hline & Female & 19 & 3.05 & 0.78 & & \\
\hline \multirow{2}{*}{ Psychological disability } & Male & 37 & 3.30 & 0.97 & \multirow{2}{*}{0.502} & \multirow{2}{*}{0.618} \\
\hline & Female & 19 & 3.16 & 1.01 & & \\
\hline \multirow{2}{*}{ Social disability } & Male & 37 & 3.30 & 0.97 & \multirow{2}{*}{0.502} & \multirow{2}{*}{0.618} \\
\hline & Female & 19 & 3.16 & 1.01 & & \\
\hline \multirow{2}{*}{ Handicap } & Male & 37 & 3.30 & 0.97 & \multirow{2}{*}{0.494} & \multirow{2}{*}{0.624} \\
\hline & Female & 19 & 3.16 & 1.01 & & \\
\hline \multirow{2}{*}{ OHIP-14 } & Male & 37 & 22.65 & 6.22 & \multirow{2}{*}{0.759} & \multirow{2}{*}{0.451} \\
\hline & Female & 19 & 21.37 & 5.46 & & \\
\hline
\end{tabular}


Table 4. Age-wise comparison of OHIP-14 scores and its domains

\begin{tabular}{|c|c|c|c|c|c|c|}
\hline Domain & $\begin{array}{l}\text { Age (in } \\
\text { years) }\end{array}$ & $\mathrm{n}$ & Mean & SD & F value & $\mathrm{p}$ value \\
\hline \multirow{3}{*}{ Functional limitation } & $<70$ & 23 & 2.78 & 1.00 & \multirow{3}{*}{1.770} & \multirow{3}{*}{0.180} \\
\hline & $71-80$ & 23 & 3.22 & 1.00 & & \\
\hline & $>80$ & 10 & 3.40 & 0.97 & & \\
\hline \multirow{3}{*}{ Physical pain } & $<70$ & 23 & 2.78 & 1.00 & \multirow{3}{*}{2.161} & \multirow{3}{*}{0.125} \\
\hline & $71-80$ & 23 & 3.30 & 0.97 & & \\
\hline & $>80$ & 10 & 3.40 & 0.97 & & \\
\hline \multirow{3}{*}{ Physical discomfort } & $<70$ & 23 & 2.78 & 1.00 & \multirow{3}{*}{2.161} & \multirow{3}{*}{0.125} \\
\hline & $71-80$ & 23 & 3.30 & 0.97 & & \\
\hline & $>80$ & 10 & 3.40 & 0.97 & & \\
\hline \multirow{3}{*}{ Physical disability } & $<70$ & 23 & 2.96 & 0.88 & \multirow{3}{*}{1.378} & \multirow{3}{*}{0.261} \\
\hline & $71-80$ & 23 & 3.30 & 0.88 & & \\
\hline & $>80$ & 10 & 3.40 & 0.70 & & \\
\hline \multirow{3}{*}{ Psychological disability } & $<70$ & 23 & 3.13 & 1.01 & \multirow{3}{*}{0.318} & \multirow{3}{*}{0.729} \\
\hline & $71-80$ & 23 & 3.30 & 0.97 & & \\
\hline & $>80$ & 10 & 3.40 & 0.97 & & \\
\hline \multirow{3}{*}{ Social disability } & $<70$ & 23 & 3.13 & 1.01 & \multirow{3}{*}{0.314} & \multirow{3}{*}{0.709} \\
\hline & $71-80$ & 23 & 3.30 & 0.97 & & \\
\hline & $>80$ & 10 & 3.40 & 0.97 & & \\
\hline \multirow{3}{*}{ Handicap } & $<70$ & 23 & 3.13 & 1.01 & \multirow{3}{*}{0.312} & \multirow{3}{*}{0.701} \\
\hline & $71-80$ & 23 & 3.30 & 0.97 & & \\
\hline & $>80$ & 10 & 3.40 & 0.97 & & \\
\hline \multirow{3}{*}{ OHIP-14 } & $<70$ & 23 & 20.70 & 6.15 & \multirow{3}{*}{1.341} & \multirow{3}{*}{0.270} \\
\hline & $71-80$ & 23 & 23.04 & 6.07 & & \\
\hline & $>80$ & 10 & 23.80 & 4.89 & & \\
\hline
\end{tabular}

\section{DISCUSSION}

Dental caries was found to be the major problems among the elderly. In our present study mean decayed teeth was reported as $3.39 \pm 0.78$ which is in accordance with the study findings of Shivakumar et al. [17] (mean 3.5). A slightly lesser prevalence was reported by Khanal et al. [9] (2.6), Agarwal et al. [1] (1.51) and Shaheen et al. [16] (1.17) among elderly populations.

The prevalence of periodontitis in our study was $(58.8 \%)$ which is comparatively less than that reported by Sha et al. [15] (71.8\%) and in the National Oral Health Survey [12] (79.4\%). Other studies conducted by Khanal et al. [9] (31\%) and Shaheen et al. [16] (47.5\%) reported a lower prevalence of periodontal disease amongst their study population.

In comparison to males, females experienced greater impact of oral diseases in all the domains of OHIP-14 and this is corroborating with the findings from a previous study conducted $[6,16]$. Handicap, psychological disability and social disabilities are most common domains reported by our study participants. Whereas in the study conducted by Krishnappa et al. [10] functional limitations and physical pain were the domains reported by the participants which affect their life.

Our study is a cross-sectional study and included only two old age homes of Kanpur city in India, which represented a certain geographic area of the city. In future a longitudinal study on larger sample size is advocated so as to assess the impact of oral diseases on oral health related quality of life of institutionalized elderly people and its wider implication on masses.

\section{CONCLUSION}

Poor oral health status was observed in the institutionalized elderly in Kanpur, India, with edentulism and periodontitis which is associated with more OHIP scores. Elderly residing at old age home do not have healthy body and oral health because they lack care and funds. Almost everyone and especially elderly require some sort of dental treatment. Involvement of government, non-government organizations and also private organizations may improve their oral health and general health conditions. 


\section{Acknowledgements}

The authors would like to thank the study participants and their parents for their participation and kind cooperation throughout the study.

\section{Authors contributions}

$A S, R N$ and $D N$ contributed with the conception, design, acquisition, analysis and interpretation of data and took part in drafting of the manuscript, critical revision and final approval. MA and GR contributed with design, analysis and interpretation of data, drafting of the manuscript and revised it critically until final approval. All authors listed on the title page have read the manuscript, attest to the validity and legitimacy of the data and its interpretation, and agree to its submission.

\section{Conflict of interest}

None declared.

\section{Source of funding}

This research did not receive any specific grant from funding agencies in the public, commercial or not-forprofit sectors.

\section{REFERENCES}

1. Agrawal R., Gautam N.R., Kumar P.M., Kadhiresan $R$., Saxena V., Jain S.: Assessment of dental caries and periodontal disease status among elderly residing in old age homes of Madhya Pradesh. J Int Oral Health 2015;7(8):57-64.

2. Amarya S., Singh K., Sabharwal M.: Changes during aging and their association with malnutrition. J Clin Gerontol Geriatr 2015;6(3):78-84.

3. Bharti R., Chandra A., Tikku A.P., Arya D., Gupta R.: Oral care needs, barriers and challenges among elderly in India. J Indian Prosthodont Soc 2015;15:17-22.

4. de Lima C.B.V., Moraes F.L., Cristine Souza L.A.: Nutritional status and associated factors in institutionalized elderly. J Nutr Disorders Ther 2012;2:116.

5. Evans C.: Malnutrition in the elderly: a multifactorial failure to thrive. Perm J 2005;9:38-41.

6. Goel P., Singh K., Kaur A., Verma M.: Oral healthcare for elderly: identifying the needs and feasible strategies for service provision. Indian J Dent Res 2006;17:11-21.
7. Griffin S.O., Jones J.A., Brunson D., Griffin P.M., Bailey W.D.: Burden of oral disease among older adults and implications for public health priorities. Am J Public Health. 2012;102(3):411-418.

8. Hickson M.: Malnutrition and ageing, Postgrad Med J 2006;82:2-8.

9. Khanal S., Bhattarai R., Rao G.N., Shrestha S.: Institutionalized elderly people oral health status and treatment needs assessment in Kathmandu district. J Dent Allied Sci 2018;7:8-12.

10. Krishnappa P., Malu M., Piddennavar R.: Assessing impact of oral diseases on oral health related quality of life of institutionalized elderly using OHIP-14 in Bengaluru: A cross-sectional study. IOSR Journal of Dental and Medical Sciences 2013;6(6):57-64.

11. Leslie W., Hankey C.: Aging, nutritional status and health. Healthcare (Basel) 2015;3:648-658.

12. National Oral Health Survey and Fluoride Mapping, 2002-2003. New Delhi: Dental Council of India, Ministry of Health and Family Welfare, Govt. of India, 2004.

13. Rajan S.I., Misra U.S., Sharma P.S.: India's Elderly: Burden or Challenge? New Delhi: Sage; 1999.

14. Razak P.A., Richard K.M., Thankachan R.P., Hafiz K.A., Kumar K.N., Sameer K.M.: Geriatric oral health: a review article. J Int Oral Health. 2014;6:110-116.

15. Sha S.K., Khan A., Eswara K., Venkata Suvarna D.L.P., Kannaiyan K., Pottem N.: Assessment of Periodontal Health and Necessity of Dental Treatment in the Institutionalized Elderly Population of East Godavari District, Andhra Pradesh. J Pharm Bioallied Sci. 2019;11(Suppl 2):S188-S193.

16.Shaheen S.S., Kulkarni S., Doshi D., Reddy S., Reddy $P$.: Oral health status and treatment need among institutionalized elderly in India. Indian J Dent Res 2015;26:493-499.

17. Shivakumar K.M., Patil S., Kadashetti V., Raje V.: Oral health-related quality of life of institutionalized elderly in Satara District, India. J. Datta Meghe Inst Med Sci Univ 2018; 13: 183-189.

18. Slade G.D.: Derivation and validation of a short-form oral health impact profile. Community Dent Oral Epidemiol 1997;25(4):284-290.

19. World Health Organisation. Oral Health Surveys: Basic Methods $4^{\text {th }}$ ed. Geneva: World Health Organisation, 1997.

Received: 21.03 .2020

Accepted: 03.08.2020 